\title{
Anatomy of an Endogenous Antagonist: Relationship between Agouti-Related Protein and Proopiomelanocortin in Brain
}

\author{
Didier Bagnol,, ${ }^{1,4}$ Xin-Yun Lu, ${ }^{1}$ Christopher B. Kaelin, ${ }^{3}$ Heidi E. W. Day, ${ }^{1}$ Michael Ollmann, ${ }^{3}$ Ira Gantz, ${ }^{2}$ \\ Huda Akil, ${ }^{1}$ Gregory S. Barsh, ${ }^{3}$ and Stanley J. Watson ${ }^{1}$ \\ ${ }^{1}$ Mental Health Research Institute and ${ }^{2}$ Department of Surgery, University of Michigan, Ann Arbor, Michigan 48109-0720, \\ ${ }^{3}$ Departments of Pediatrics and Genetics, Howard Hughes Medical Institute, Stanford, California 94305, and ${ }^{4}$ Centre \\ National de la Recherche Scientifique, Neurobiologie des Fonctions Végétatives, Université d'Aix-Marseille, Marseille 3, \\ Cedex 20, France
}

Agouti-related protein (AGRP) is a recently discovered orexigenic neuropeptide that inhibits the binding and action of $\alpha$-melanocyte-stimulating hormone derived from proopiomelanocortin (POMC) at the melanocortin 3 receptor (MC3R) and melanocortin 4 receptor (MC4R) and has been proposed to function primarily as an endogenous melanocortin antagonist. To better understand the interplay between the AGRP and melanocortin signaling systems, we compared their nerve fiber distributions with each other by immunohistochemistry and their perikarya distribution with MC3R and MC4R by double in situ hybridization. Although deriving from distinct cell groups, AGRP and melanocortin terminals project to identical brain areas. Both AGRP and melanocortin neurons selectively express the MC3R, which provides a neuroanatomical basis for a dual-input circuit with biological amplification and feedback inhibition. These studies highlight a broader complexity in POMC-mediated behavior in the brain.

Key words: Agouti-related protein; proopiomelanocortin; ingestive behavior; MC3R; MC4R; arcuate nucleus
Naturally occurring antagonists can act either by binding to and sequestering a ligand or by binding to a receptor to prevent its response to another molecule. Unique advantages for biological regulation are provided by the latter mechanism, of which Agouti protein and Agouti-related protein (AGRP) are prime examples (Ollmann et al., 1997, 1998; Shutter et al., 1997). These proteins inhibit the activity of melanocortins, small peptides such as $\alpha$-melanocyte-stimulating hormone ( $\alpha$-MSH) or adrenocorticotrophic hormone derived from a large precursor, proopiomelanocortin (POMC), that also gives rise to $\beta$-endorphin. AGRP binds directly to melanocortin receptors but has little intrinsic signaling activity, and instead functions primarily by inhibiting $\alpha$-MSH binding (Ollmann et al., 1997; Shutter et al., 1997). Indeed, the melanocortin receptors were originally identified by their ability to activate adenylate cyclase in response to $\alpha$-MSH. However, recent studies have suggested that physiological modulation of receptor signaling may be accomplished mainly by alteration in the levels of AGRP rather than $\alpha$-MSH. Starvation and leptin deficiency cause a predominant rise in levels of AGRP mRNA rather than a decrease in POMC mRNA levels in the hypothalamus (Thornton et al., 1997; Mizuno et al., 1998; Mizuno Mobbs, 1999; Wilson et al., 1999). Artificial increases in AGRP achieved pharmacologically or in transgenic animals cause elevated food

Received May 21, 1999; revised July 15, 1999; accepted July 21, 1999.

This work was supported by National Institutes of Health Grants P01 MH-42251 (from National Institute of Mental Health; to S.J.W.), DK28506 (to G.S.B.), and R01 DK-54032-01 (to I.G.). We thank Sharon Burke and Robert Pavlic for technical assistance and Drs. Serge Campeau and Manuel Lopez-Figueroa for advice and comments.

D.B. and X.-Y.L. contributed equally to this work

Correspondence should be addressed to Stanley J. Watson, Mental Health Research Institute, The University of Michigan, 205 Zina Pitcher Place, Ann Arbor, MI 48109-0720.

Copyright (C) 1999 Society for Neuroscience 0270-6474/99/190001-07\$05.00/0 intake and obesity (Graham et al., 1997; Ollmann et al., 1997; Grill et al., 1998; Rossi et al., 1998).

Because the action of AGRP has only been tested on melanocortin receptors, the question remains, does AGRP work primarily as a melanocortin antagonist, or might it have other functions? One approach to this question is to examine its anatomy vis-a-vis the anatomy of the melanocortins and to determine whether AGRP only exists where melanocortins are found, or whether it is also expressed at other sites independent of either the ligands or the receptor(s) that it is purported to antagonize. To investigate the potential for presynaptic and/or direct crosstalk between AGRP and POMC systems, we examined the colocalization of AGRP or POMC with the MC3R and MC4R using double in situ hybridization.

\section{MATERIALS AND METHODS}

Animals. Male Sprague Dawley rats (Charles River Laboratories, Wilmington, MA) weighing 300-350 gm were used in this study. Rats were housed in groups of two or three per cage with food and water available ad libitum in a $12 \mathrm{hr}$ light/dark cycle (lights on at 7 A.M.) under conditions of constant temperature and humidity. Animals were allowed to habituate for 1 week before experiments. Protocols for animal exper-

This article is published in The Journal of Neuroscience, Rapid Communications Section, which publishes brief, peerreviewed papers online, not in print. Rapid Communications are posted online approximately one month earlier than they would appear if printed. They are listed in the Table of Contents of the next open issue of JNeurosci. Cite this article as: JNeurosci, 1999, 19:RC26 (1-7). The publication date is the date of posting online at www.jneurosci.org.

http://www.jneurosci.org/cgi/content/full/3484 
Table 1. Distribution and relative abundance of AGRP- and POMCimmunoreactive fibers and terminals in the rat CNS

\begin{tabular}{l} 
Anatomical sites \\
\hline Telencephalon \\
Anterior olfactory nucleus, posterior part \\
Olfactory tubercle \\
Cingulate cortex \\
Infralimbic cortex \\
Ventral orbital cortex \\
Endopiriform nucleus \\
Accumbens nucleus \\
Shell \\
Core
\end{tabular}

Substantia innominata

Anterior amygdaloid area

Anterior cortical amygdaloid nucleus

Central nucleus

Medial division

Lateral division

Medial amygdaloid nucleus

Basomedial amygdaloid nucleus

$$
\begin{aligned}
& \text { Anterior part } \\
& \text { Ventral part }
\end{aligned}
$$

Bed nucleus of stria terminalis

Ventral division

Medial division

Lateral division

Supracapsular division

Lateral septum:

Ventral part

Dorsal division

Medial septum ventral

Nucleus of the diagonal band

Subfornical organ

Diencephalon

Medial habenular nucleus

Paraventricular thalamic nucleus

Paratenial thalamic nucleus

Laterodorsal thalamic nucleus, ventrolateral part

Stria terminalis

Nucleus of stria medullaris

Zona incerta

Strial part of the preoptic area

Striohypothalamic nucleus

Organum vasculosum of the lamina terminalis

Medial preoptic area

Median preoptic nucleus

Anteroventral preoptic nucleus

Lateral preoptic area

Supraoptic nucleus

Suprachiasmatic nucleus

Anterior hypothalamic nucleus

Paraventricular hypothalamic nucleus

Magnocellular division

Parvocellular division

Periventricular hypothalamic nucleus

Retrochiasmatic area

Ventromedial hypothalamic nucleus

Dorsomedial hypothalamic nucleus

Dorsal part

$+\quad+$

\section{Table 1. Continued}

Anatomical sites

Agrp $\quad \gamma-\mathrm{MSH}$

Compact

Ventral part

Dorsal hypothalamic area

Lateroanterior hypothalamic nucleus

Lateral hypothalamic area

Ventrolateral hypothalamic nucleus

Perifornical nucleus

Posterior hypothalamic area

Arcuate nucleus

Median eminence, internal part

Median eminence, external part

Medial tuberal nucleus

Supramammillary nucleus

Mesencephalon

Substantia nigra compact

Ventral tegmental area

Intrafascicular nucleus

Interpeduncular nucleus

Rostral linear nucleus raphe

Periacqueductal gray

Edinger-Westphal nucleus

Dorsal raphe nucleus

Precommissural nucleus

Commissure of the superior colliculus

Medial pretectal nucleus

Deep mesencephalic nucleus

Anterior pretectal nucleus, ventral part

Peripedoncular nucleus

Metencephalon

Cerebellum

Parabrachial nucleus, lateral part

Parabrachial nucleus, medial part

Locus coeruleus

Subcoeruleus nucleus

Motor trigeminal nucleus

Mesencephalic trigeminal nucleus

Pontine reticular nucleus

Pontine reticular nucleus caudal

Principal sensory trigminal nucleus, ventrolateral

$\begin{array}{cc}- & - \\ +++ & ++++\end{array}$

$++\quad++$

$+\quad+++$

$+++\quad+++$

$++\quad++$

$+++\quad+++$

$+\quad++$

$++++\quad++++$

$+++\quad+++$

$+\quad+$

$++\quad+++$

$+\quad++$

$\begin{array}{ll}- & ++\end{array}$

$+1-\quad++$

$+1-\quad+$

$+1-\quad+$

$+1-\quad+$

$+(+) \quad++(+)$

$+/-\quad+$

$+(+) \quad+++$

$+\quad++$

$+\quad+$

$-\quad+$

$-\quad++$

$-\quad+$

$-\quad+$

Myelencephalon

Raphe magnus nucleus

A5 Noradrenaline cells

Gignatocellular reticular nucleus

Nucleus of solitary tract, median part

Nucleus of solitary tract, lateral part

Ambigus nucleus

Spinal cord (cervical)

Spinal cord layers 1-7, 10

Lateral funiculus of the spinal cord

Pituitary gland

Posterior pituitary

$-\quad-$

$++\quad+++$

$+/-\quad+(+)$

$++\quad+++$

$+1-\quad+$

$++\quad+++$

$++\quad++$

$+1-\quad++$

$-\quad+$

- +

$-\quad+(+)$

$-\quad+$

$-\quad+$

$+\quad++$

$(+) \quad+(+)$

$+++$

$-\quad+1-$

$-\quad++$

$++++$

$++++\quad+++$

$+++\quad++$

$+++++++$

$++++\quad+++$

$++\quad+++$
The density of immunoreactive fibers is estimated and indicated as - , undetectable immunoreactivity; $+/-$, occasional single fibers; + , light density; ++ , moderate;

+++ , dense; ++++ , heavy; and +++++ , compact, with parentheses representing intermediate levels. 
imentation were approved by the University of Michigan Institutional Animal Care and Use Committee.

Immunohistochemistry. For immunohistochemical studies male unfasted Sprague Dawley rats were perfused via the ascending aorta with a Zamboni's fixative solution, and brains were removed, immersion-fixed, cryoprotected, frozen, and sectioned. Thirty-micrometer-thick freefloating sections were incubated or co-incubated with human AGRP affinity-purified antibody $(1: 30,000)$ or $\gamma 3$-MSH (Lys-Tyr-Val-Met-GlyHis-Phe-Arg-Trp-Asp-Arg-Phe-Gly-Pro-Arg-Asn-Ser-Ser-Ser-Ala-GlyGly-Ser-Ala-Gln, coupled to thyroglobulin with glutaraldehyde) antibody $(1: 20,000)$ following a procedure previously described (Wilson et al., 1999).

In situ hybridization histochemistry. For in situ hybridization histochemistry male Sprague Dawley rats were killed by rapid decapitation $(2 \mathrm{hr}$ after lights on), and brains were removed and frozen. A $345 \mathrm{bp}$ fragment of the rat AGRP cDNA and a $936 \mathrm{bp}$ fragment of the rat POMC cDNA were used to synthesize antisense cRNA probes. The rat MC3R (2811270) probe was generated by PCR using Pfu polymerase (Statagene, La Jolla, CA) with genomic DNA as a substrate, and the rat MC4R (1411181) probe was generated by screening a rat EMBL3 genomic library (Clontech, Palo Alto, CA) using the human MC4R as a probe. Digoxigenin-11-UTP (Boehringer Mannheim, Mannheim, Germany) antisense-labeled rat AGRP or POMC probes and $\left[\alpha^{-35}\right.$ S]UTP and $\left[\alpha^{-35}\right.$ S $]$ CTP (Amersham, Arlington Heights, IL) antisense-labeled MC3R or MC4R probes were simultaneously hybridized on paraformaldehyde-fixed setions as previously described by Curran and Watson (1995) and Wilson et al. (1999).

The specificity of hybridization was confirmed by control experiments using sense probes or tissue that had been pretreated with ribonuclease A $(200 \mu \mathrm{g} / \mathrm{ml})$ for $1 \mathrm{hr}$ at $37^{\circ} \mathrm{C}$ before hybridization with antisense probes. No specific hybridization signals were observed in these conditions.

Photomicrography and image analysis. The immunostained and autoradiographic tissue sections were viewed using a Leica (Nussloch, Germany) DMR microscope, and images were captured with an MCID M5 image analysis system (Imaging Research, St. Catherine's Ontario, Canada). Images were prepared with Adobe (Mountain View, CA) Photoshop 4.0 software, and only the contrast or transparency was adjusted. For double in situ hybridization, nonradioactive labeling was visualized under bright field as a blue precipitate, and radioactive labeling was identified under dark field by silver grain clusters. Digoxigenin-labeled neurons (AGRP or POMC mRNA-containing neurons) were counted bilaterally and then examined for the presence of silver gains (either MC3R or MC4R). A series of sections spaced $100 \mu \mathrm{m}$ apart was analyzed for each set of probes. No attempt was made to determine the total number of cells in the arcuate nucleus; therefore, the cell counting data represent a relative percentage of AGRP or POMC cells expressing MC3R rather than an absolute number. The boundaries of nuclei were determined according to the atlases of Kruger et al. (1995) and Paxinos and Watson (1986).

\section{RESULTS}

\section{Co-distribution of AGRP- and POMC-immunoreactive nerve fibers in the brain}

Previous studies by us and other groups have indicated that the POMC and AGRP systems were derived from two distinct cell populations in the arcuate nucleus (Shutter et al., 1997; Hahn et al., 1998; Wilson et al., 1999). In the present study, we compared AGRP and POMC projections in the brain, spinal cord, and pituitary with adjacent sections. Immunoreactive POMC processes were widely distributed throughout the brain (Table 1), exhibiting a projection pattern identical to that previously described for other POMC-derived peptides such as $\beta$-endorphin and $\alpha$-MSH (Watson et al., 1978a,b; Khachaturian et al., 1985). AGRP fibers essentially overlapped with POMC projections. Three major projectional systems of AGRP fibers could be delineated as has been described for the POMC system (Khachaturian et al., 1985): rostral, lateral, and caudal systems. The rostral and
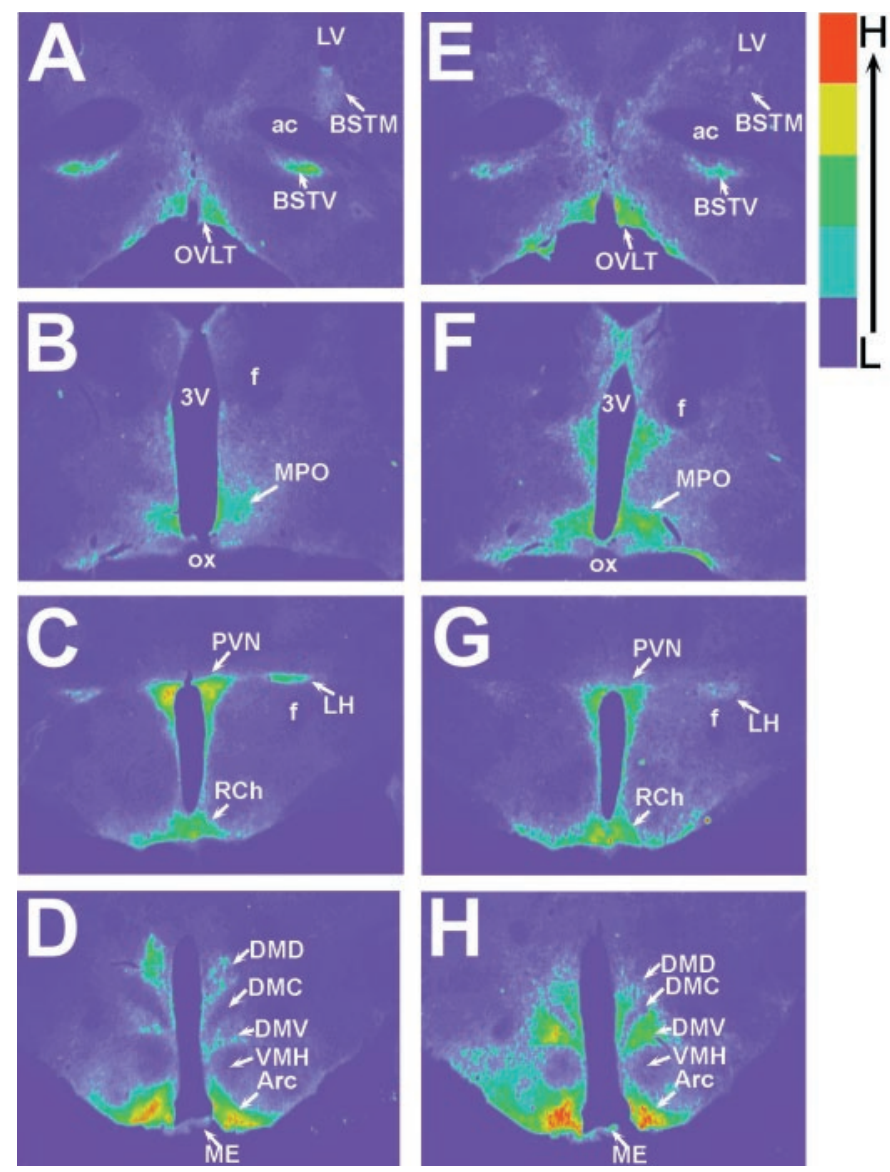

Figure 1. Color scale illustration of AGRP $(A-D)$ and POMC $(E-H)$ immunoreactivity in the rat brain. Images of coronal brain sections were acquired with NIH Image software. The intensity of the labeling ranges from blue (low, $L$ ) to red (high, $H$ ), which is a summation of density of fibers and intensity of immunostaining per fiber. The distribution patterns of AGRP and POMC are very similar. Note the high intensity of AGRPimmunoreactive fibers in bed nucleus of the stria terminalis, ventral division $(B S T V ; A)$, organum vasculosum lamina terminalis $(O V L T ; A)$, medial preoptic nucleus $(M P O ; B)$, paraventricular hypothalmic nucleus $(P V N ; C)$, retrochiasmatic area $(R c h ; C)$ lateral hypothalamus $(L H ; C)$, and arcuate nucleus $(A r c ; D)$. $a c$, Anterior commissure; $D M D$, dorsomedial hypothalamic nucleus, diffuse; $D M C$, dorsomedial hypothalamic nucleus, compact; $M E$, median eminence; $V M H$, ventromedial hypothalamic nucleus.

lateral projections of AGRP in the forebrain were prominent and closely paralleled the rostral and lateral POMC projections (Fig. 1). Within the same fields, POMC projections were more broadly distributed. AGRP-immunoreactive fibers appeared to be thinner and to have more varicosities than POMC fibers. AGRP terminals were densely packed to form compact immunoreactive patches in some forebrain regions, such as the bed nucleus of the stria terminalis, ventral division, the organum vasculosum of the lamina terminalis, the paraventricular nucleus of the hypothalamus, the arcuate nucleus, the dorsomedial nucleus of the hypothalamus, and the perifornical nucleus and lateral hypothalamus (Figs. $1,2,3 E-H)$. These findings of the distribution of AGRP immunoreactivity were consistent with the recent reports as described in the mouse, diestrous rat, and fasted monkey (Broberger et al., 1998; Haskell-Luevano et al., 1999). In the caudal projections to the brainstem and spinal cord, POMC innervation was much heavier and broader than that of AGRP, as shown in Table 1. AGRP was greatly reduced or absent from many POMC- 

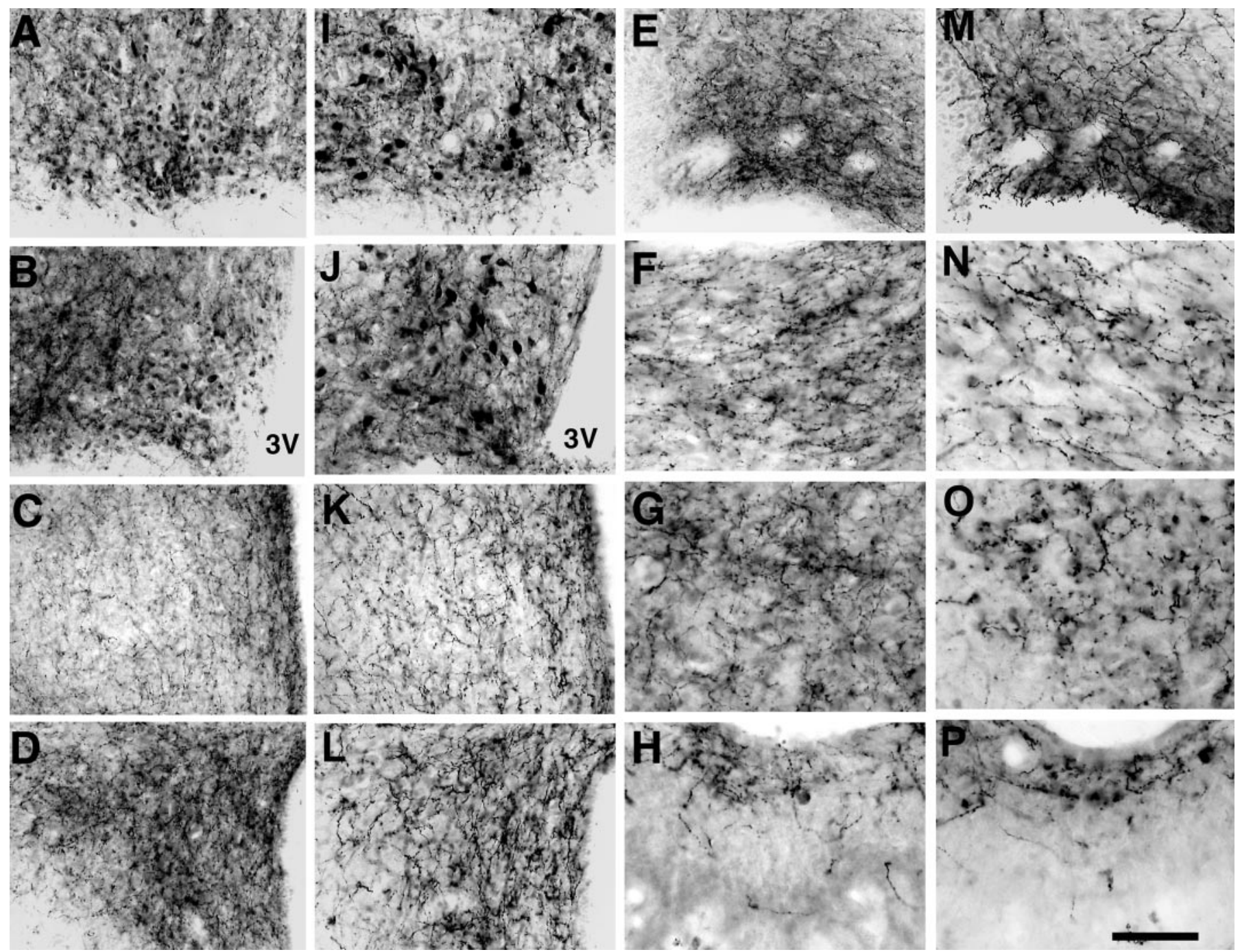

Figure 2. Photomicrographs illustrating AGRP $(A-H)$ and POMC $(I-P)$ immunohistochemistry in the hypothalamic nuclei. Areas include Rch $(A, I)$, $\operatorname{Arc}(B, J)$, MPO $(C, K)$, PVN $(D, L)$, OVLT $(E, M)$, BSTV $(F, N)$, paraventricular nucleus of the thalamus $(G, O)$, and ME $(\mathrm{H}, \mathrm{P})$. Note the small size of AGRP immunoreactive perikarya versus large POMC immunoreactive perikarya in the Rch and Arc $(A, B, I, J)$. The density of AGRP immunoreactive fibers is more prominent than for POMC fibers in the $\operatorname{Arc}(B, J), \operatorname{PVN}(D, L)$, and BSTV $(F, N)$. Note the presence of moderate to dense innervation of AGRP and POMC in the internal part of the median eminence. $3 V$, Third ventricle; other abbreviations as in Figure 1. Scale bars, $100 \mu \mathrm{m}$.

innervated areas in the brainstem and cervical spinal cord (Table 1), suggesting that a substantial portion of the caudal POMC system originates from cells in the nucleus of the solitary tract Bronstein et al., 1992, whereas the rostral and lateral projections of POMC and AGRP probably originate in parallel from the arcuate nucleus of the hypothalamus.

Using double-labeling immunohistochemistry, we found that AGRP fiber boutons were closely apposed to POMC neurons in the arcuate nucleus (Fig. 3E). These findings suggest that AGRP and POMC neurons interact locally in their cell body regions and are consistent with the observation that NPY neurons (which always contain AGRP in the arcuate nucleus) make synaptic contact with POMC neurons (Csiffary et al., 1990).

\section{Expression of melanocortin receptors by AGRP or POMC cells}

Colocalization of MC3R/MC4R with AGRP and POMC cells was first investigated in the present study. We found that MC3R mRNA was contained in both AGRP and POMC neurons with a rostrocaudal gradient in the arcuate nucleus (Arc). MC3R mRNA was identified in 55\% of AGRP neurons in rostral Arc and in $28 \%$ for the most caudal Arc sections (Fig. 3A) with an average of $44 \%$ (all of the Arc sections counted). Similarly, we found that MC3R mRNA was expressed in 43\% of POMC neurons in rostral Arc and $13 \%$ for the most caudal sections (Fig. 3B) with an average of $31 \%$ (all Arc sections counted). In contrast, neither AGRP nor POMC cells displayed MC4R mRNA (Fig. 3C,D).

\section{DISCUSSION}

In the present study we extended the recent reports about AGRP projections in the CNS and compared the distribution of AGRP and POMC systems with each other with double immunohistochemistry methods as well as with melanocortin receptor subtypes using double in situ hybridization techniques.

Anatomical coregistration of AGRP with POMC peptides demonstrated by our study implies that AGRP might be completely dependent on the melanocortin receptors for its actions. 

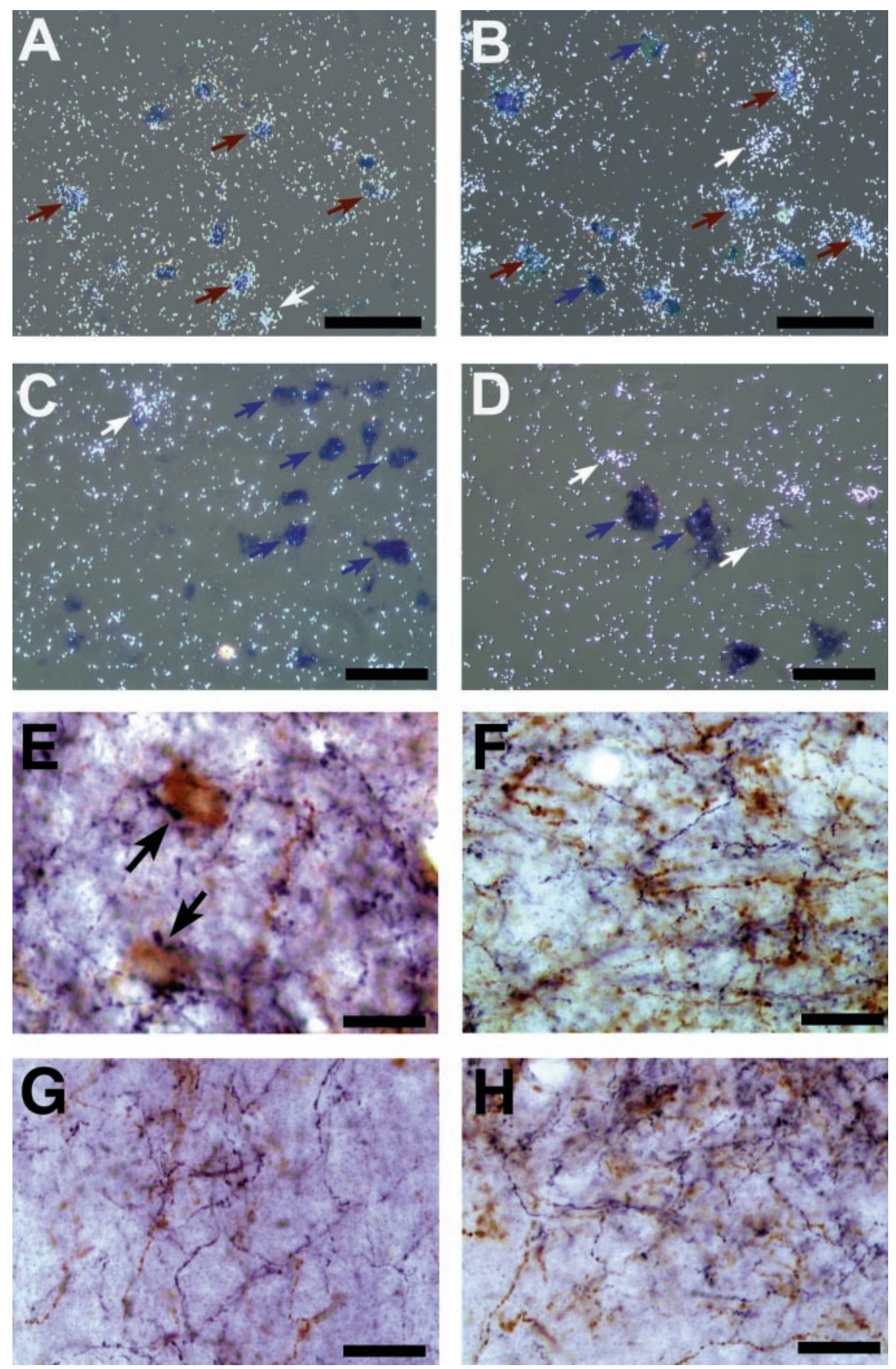

Figure 3. $A-D$, Representative photomicrographs of double in situ hybridization histochemistry indicating that AGRP or POMC mRNA colocalize with MC3 receptor mRNA $(A, B)$, but not with MC4 receptor mRNA $(C, D)$. The white silver grain clusters represent MC3 or MC4 receptor mRNAs, which were detected by ${ }^{35} \mathrm{~S}$-labeled riboprobes. AGRP $(A, C)$ and POMC $(B, D)$ mRNAs were visualized by digoxigeninlabeled riboprobes (in blue). Thirty-one to $44 \%$ of AGRP $(A)$ and POMC $(B)$ cells expressed MC3R (red arrows), whereas none of them displayed MC4R (in $C$, $D$, respectively AGRP and POMC cells). Some MC3R and MC4R cells contained other neurotransmitters than AGRP and POMC ( $A-D$, white arrows). Some AGRP and POMC cells do not display MC3R and MC4R ( $B-D$, blue arrows). $E-H$, Double-labeling immunohistochemistry on coronal brain sections showing both AGRP- and POMC-immunoreactive fibers in the arcuate nucleus $(E)$, lateral hypothalamus $(F)$, central amygdala $(G)$, and dorsomedial hypothalamus $(H)$. $\gamma 3$-MSH immunoreactivity was detected by DAB (in brown), whereas AGRP immunoreactivity was detected by $\mathrm{NiCl}$ amplification (in black). Note in $E$ POMC-immunoreactive cells being surrounded by AGRP-immunoreactive fibers (arrows), suggesting synaptic contact between AGRP fibers and POMC neurons. Scale bars: $A, B, 50 \mu \mathrm{m} ; C, D, F-H, 25 \mu \mathrm{m}$; $E, 15 \mu \mathrm{m}$.
This is supported by in vitro data indicating that AGRP suppresses MSH-induced cAMP accumulation via either MC3R or MC4R (Ollmann et al., 1997). Comparing MCR mRNA distribution and AGRP terminal projections reveals a strong overlap in most areas rich in MC3R mRNA and a subset of areas expressing MC4R mRNA (Roselli-Rehfuss et al., 1993; Mountjoy et al., 1994). In addition, we found a good correlation between AGRP projection fields and the reported MCR binding sites (Tatro, 1990). These observations strongly support the hypothesis that MCRs are the putative receptors for AGRP, although we cannot rule out the possibility of the existence of distinct AGRP receptors that might be distributed identically to MCRs.

The wide distribution of AGRP terminals suggest that AGRP participates in the regulation of food consumption through sev- eral hypothalamic structures, including the paraventricular, arcuate, dorsomedial, and lateral hypothalamic nuclei, as well as the amygdala, an area implicated in emotional aspects of feeding behavior. Interestingly, AGRP and POMC-immunoreactive fibers are not found in the ventromedial hypothalamic nucleus, even though this region contains abundant MC3R mRNA and $\alpha$-MSH binding sites and has been referred to historically as a "satiety center" (Brobeck, 1946). These discrepancies could reflect functional receptor trafficking to the axon terminals. Besides feeding behavior likely mediated by hypothalamic regions, the widespread co-distribution of AGRP and POMC projections in the forebrain and brainstem implicates AGRP in the control of other behaviors or functions attributed to POMC, including stress, thermoregulation, pain, and reproduction (Khachaturian 
et al., 1985). We also observed AGRP and POMC fibers in the internal layer of the median eminence. These fibers extend into the posterior lobe of the pituitary and suggest that AGRP could be released into the systemic circulation and function as an endocrine hormone.

The presence of MC3R in both AGRP and POMC neurons demonstrated by the present study suggests that MC3R may mediate the potential interaction between AGRP and POMC systems. Moreover, the colocalization of Mc3R with AGRP and POMC neurons suggest that MC3R may act at the upstream of MC4R in the control of food intake. Because activation of MC3R by melanocortins is stimulatory (i.e., it increases levels of cAMP), and its blockade by AGRP is inhibitory, we would propose two possible roles for MC3R in the POMC and AGRP neuronal circuit. Expression of the MC3R by POMC neurons provides a potential circuit for amplification of AGRP-mediated signals, because AGRP-induced inhibition of POMC neurons via the MC3R would reinforce the postsynaptic effects of AGRP. Furthermore, the expression of the MC3R by AGRP neurons provides a potential circuit for negative autoregulation of POMCmediated signals, because POMC-induced activation of AGRP neurons via the MC3R would terminate the postsynaptic effects of POMC. Both of these types of actions would tend to reinforce orexigenic behavior but limit signals for satiety and may explain why AGRP or other melanocortin antagonists exert a prolonged effect after intracerebroventrical administration (Grill et al., 1998; Rossi et al., 1998). From an evolutionary perspective, biological amplification of food-seeking behavior and/or feedback inhibition of satiety behavior may offer a selective advantage in situations in which reproductive success is limited by nutrient availability. Given the colocalization of AGRP with NPY (Broberger et al., 1998; Hahn et al., 1998) (D. Bagnol, X.-Y. Lu, and S. J. Watson, unpublished observations) and of POMC and CART (cocaine- and amphetamine-regulated transcript; Elias et al., 1999), it is further suggested that regulation of AGRP and POMC neurons could be accomplished not only via MC3R but also by NPY and CART receptors to coordinate their neurotransmission.

These studies also highlight a broader complexity in POMCmediated behavior in the brain. POMC mediated behaviors can be elicited through the release of several peptides acting on several classes of receptors, including the activation of $\mu$ and $\delta$ opioid receptors by $\beta$-endorphin. AGRP might allow partial suppression of melanocortin peptide activity although leaving POMC-mediated opioid actions intact. Given that opioid and melanocortin actions can be either synergistic or antagonistic depending on the behavior under study (Khachaturian et al., 1985; Adan and Gispen, 1997), the presence or absence of AGRP activity may serve to alter the balance between these two components of POMC neurotransmission. Thus, POMC-mediated behavior would be under the control of the amount of AGRP as well as the amount and mix of POMC-derived peptides released at the terminals and the presence of melanocortin receptors or opioid receptors in their vicinity. This represents a novel mechanism whereby a multitransmitter neuron may have its impact selectively altered by local antagonism of one of its potentially active products. The full complexity of this type of neuronal regulation has yet to be appreciated. Still, the essential elements of this system include natural agonist-antagonist pairs, parallel neuronal fiber pathways, possible coordination of cross-regulation via shared receptors, and the actions of other co-transmitters. This level of regulation suggests several new principles of neuro- transmitter signaling and may apply to other newly discovered endogenous antagonists, such as the recently reported 5-HTmoduline, a naturally occurring peptide antagonist that blocks the action of 5-HT at the 5-HT1B receptor (Massot et al., 1996).

\section{REFERENCES}

Adan RA, Gispen WH (1997) Brain melanocortin receptors: from cloning to function. Peptides 18:1279-1287.

Brobeck JR (1946) Mechanism of the development of obesity in animals with hypothalamic lesions. Physiol Rev 26:541-559.

Broberger C, Johansen J, Johansson C, Schalling M, Hôkfelt T (1998) The neuropeptide Y/agouti gene-related protein (AGRP) brain circuitry in normal, anorectic, and monosodium glutamate-treated mice. Proc Natl Acad Sci USA 95:15043-15048.

Bronstein DM, Schafer MK, Watson SJ, Akil H (1992) Evidence that beta-endorphin is synthesized in cells in the nucleus tractus solitarius: detection of POMC mRNA. Brain Res 587:269-275.

Csiffary A, Gorcs TJ, Palkovits M (1990) Neuropeptide Y innervation of ACTH-immunoreactive neurons in the arcuate nucleus of rats: a correlated light and electron microscopic double immunolabeling study. Brain Res 506:215-222.

Curran EJ, Watson SJ (1995) Dopamine receptor mRNA expression patterns by opioid peptide cells in the nucleus accumbens of the rat: a double in situ hybridization study. J Comp Neurol 361:57-76.

Elias CF, Lee C, Kelly J, Aschkenasi C, Ahima RS, Couceyro PR, Kuhar MJ, Saper CB, Elmquist JK (1999) Leptin activates hypothalamic CART neurons projecting to the spinal cord. Neuron 21:1375-1385.

Graham M, Shutter JR, Sarmiento U, Sarosi I, Stark KL (1997) Overexpression of Agrp leads to obesity in transgenic mice. Nat Genet $17: 273-274$

Grill HJ, Ginsberg AB, Seeley RJ, Kaplan JM (1998) Brainstem application of melanocortin receptor ligands produces long-lasting effects on feeding and body weight. J Neurosci 18:10128-35.

Hahn TM, Breininger JF, Baskin DG, Schwartz MW (1998) Coexpression of Agrp and NPY in fasting-activated hypothalamic neurons. Nat Neurosci 1:271-272.

Haskell-Luevano C, Chen P, Li C, Chang K, Smith MS, Cameron JL, Cone RD (1999) Characterization of the neuroanatomical distribution of agouti-related protein immunoreactivity in the rhesus monkey and the rat. Endocrinology 140:1408-1415.

Khachaturian H, Lewis ME, Tsou K, Watson SJ (1985) $\beta$-endorphin, $\alpha$-MSH, ACTH, and related peptides. In: Handbook of chemical neuroanatomy: GABA and neuropeptides in the CNS, Pt 1, Vol 4 (Bjørklund A, Hôkfelt T, eds), pp 216-272. Amsterdam: Elsevier.

Kruger L, Saprota S, Swanson L (1995) Photographic atlas of the rat brain: the cell and fiber architecture illustrated in three planes with stereotaxic coordinates. New York: Cambridge UP.

Massot O, Rousselle JC, Fillion MP, Grimaldi B, Cloez-Tayarani I, Fugelli A, Prudhomme N, Seguin L, Rousseau B, Plantefol M, Hen R, Fillion G (1996) 5-Hydroxytryptamine-moduline, a new endogenous cerebral peptide, controls the serotonergic activity via its specific interaction with 5-hydroxytryptamine1B/1D receptors. Mol Pharmacol 50:752-762.

Mizuno TM, Mobbs CV (1999) Hypothalamic agouti-related protein messenger ribonucleic acid is inhibited by leptin and stimulated by fasting. Endocrinology 140:814-817.

Mizuno TM, Kleopoulos SP, Bergen HT, Roberts JL, Priest CA, Mobbs CV (1998) Hypothalamic pro-opiomelanocortin mRNA is reduced by fasting and [corrected] in ob/ob and $\mathrm{db} / \mathrm{db}$ mice, but is stimulated by leptin. Diabetes 47:294-297.

Mountjoy KG, Mortrud MT, Low MJ, Simerly RB, Cone RD (1994) Localization of the melanocortin-4 receptor (MC4-R) in neuroendocrine and autonomic control circuits in the brain. Mol Endocrinol 8:1298-1308.

Ollmann MM, Wilson BD, Yang YK, Kerns JA, Chen Y, Gantz I, Barsh GS (1997) Antagonism of central melanocortin receptors in vitro and in vivo by agouti-related protein. Science 278:135-138.

Ollmann MM, Lamoreux ML, Wilson BD, Barsh GS (1998) Interaction of Agouti protein with the melanocortin 1 receptor in vitro and in vivo. Genes Dev 12: 316-330.

Paxinos G, Watson C (1986) The rat brain in stereotaxic coordinates. San Diego: Academic. 
Roselli-Rehfuss L, Mountjoy KG, Robbins LS, Mortrud MT, Low MJ, Tatro JB, Entwistle ML, Simerly RB, Cone RD (1993) Identification of a receptor for gamma melanotropin and other proopiomelanocortin peptides in the hypothalamus and limbic system. Proc Natl Acad Sci USA 90:8856-8860.

Rossi M, Kim MS, Morgan DG, Small CJ, Edwards CM, Sunter D, Abusnana S, Goldstone AP, Rossell SH, Stanley SA, Smith DM, Yagaloff K, Ghatei MA, Bloom SR (1998) A C-terminal fragment of Agouti-related protein increases feeding and antagonizes the effect of alpha-melanocyte stimulating hormone in vivo. Endocrinology 139: $4428-4431$.

Shutter JR, Graham M, Kinsey AC, Scully S, Luthy R, Stark KL (1997) Hypothalamic expression of ART, a novel gene related to agouti, is up-regulated in obese and diabetic mutant mice. Genes Dev 11:593-602.
Tatro JF (1990) Melanotropin receptors in the brain are differentially distributed and recognize both corticotropin and alpha-melanocyte stimulating hormone. Brain Res 536:124-132.

Thornton JE, Cheung CC, Clifton DK, Steiner RA (1997) Regulation of hypothalamic proopiomelanocortin mRNA by leptin in ob/ob mice. Endocrinology 138:5063-5066.

Watson SJ, Richard CW, Barchas J D (1978a) Adrenocorticotropin in rat brain: immunocytochemical localization in cells and axons. Science 200:1180-1182.

Watson SJ, Akil H, Richard III CW, Barchas JD (1978b) Evidence for two separate opiate peptide neuronal systems. Nature 275:226-227.

Wilson BD, Bagnol D, Kaelin CB, Ollmann MM, Gantz I, Watson SJ, Barsh GS (1999) Physiological and anatomical circuitry between Agouti-related protein and leptin signaling. Endocrinology 140:23872397. 